\title{
Chemopreventive potential of plant- derived epigenetic inhibitors silibinin and quercetin: an involvement of apoptotic signaling cascade modulation
}

\author{
Ruma Baksi ${ }^{1,2^{*}}$, Rita Rana ${ }^{1}$ and Manish Nivsarkar ${ }^{1}$
}

\begin{abstract}
Background: Epigenetic deregulation of the cellular apoptotic mechanism is the common hallmark of cancer. Silibinin (SBN) and quercetin (QCT) are two bioflavonoids well known for their epigenetic inhibition property. The objective of the present study was to explore the preventive anti-cancer efficacy of the SBN and QCT in both in vitro as well as in vivo tumor xenograft model through regulating cellular apoptotic signaling pathway.

Results: SBN and QCT inhibited the growth of A549 and MDA-MB-468 cancer cells in the concentration dependent manner. The treatment caused significant $(p<0.05)$ reduction of the size and the number of colonies formed by the cancer cells. In vitro apoptosis assay using the fluorescence microscopy revealed that the treatment noticeably increased the percentage of apoptotic cells as compared to the untreated control. Dosing with SBN $(200 \mathrm{mg} / \mathrm{kg})$, QCT $(100 \mathrm{mg} / \mathrm{kg})$ alone and in combination was initiated in 3-week-old C57BL6 mice. Interestingly, the treatment prevented tumor progression significantly $(p<0.05)$ in adult mice without causing any toxicity. Furthermore, SBN and QCT triggered apoptosis via modulating p53 and Bcl2 gene expression and the SOD enzyme activity.

Conclusion: Daily oral intake of SBN and QCT alone and in combination from the very early stage of life might prevent tumor growth in adult mice through activating cellular apoptotic signaling cascade.
\end{abstract}

Keywords: Cancer xenograft, Quercetin, Silibinin, Apoptosis, Gene expression, SOD

\section{Background}

Cancer is still an unsolved problem of human being and a primary cause of morbidity and mortality. According to International Agency for Research on Cancer (IARC) and GLOBOCAN 2018, the total incidence of new cancer cases and cancer deaths in 2018 was 17.0 and 9.5 million respectively excluding nonmelanoma skin cancer [1]. Global cancer statistics 2018 claims that among males, lung cancer is the most diagnosed cancer cases

\footnotetext{
* Correspondence: ruma.baksi@gmail.com

'Department of Pharmacology and Toxicology, B. V. Patel Pharmaceutical

Education and Research Development (PERD) Centre, Thaltej, Ahmedabad, Gujarat 380054, India

${ }^{2}$ Institute of Science, NIRMA University, Sarkhej-Gandhinagar Highway, Ahmedabad, Gujarat 382481, India
}

\section{Springer Open}

(14.5\%) and major cause of cancer mortality (22.0\%) [1, $2]$, whereas breast cancer is the highest estimated cancer incidences (24.2\%) and cancer deaths (15.0\%) in females $[1,2]$. Though the latest diagnostic techniques and chemotherapeutic treatments have improved the fate of cancer patients, yet cancer is a major social burden.

Normal cells of our body multiply under commands of specific cellular signals and undergo senescence or apoptosis as they grow old [3]. Apoptosis is a controlled cell death mechanism guided by various interconnected molecular and biochemical cell signaling pathways [3]. The latest investigations in oncogenesis revealed that epigenetic alterations followed by permanent genetic transformations of tumor suppressor genes (TSGs) and protooncogenes involved in regulating cell growth and 
apoptosis are the prime cause of cancer [4]. The TSG, p53 also known as "guardian of cells" and protooncogene $\mathrm{Bcl} 2$ play a crucial role in cell death and survival by regulating cellular apoptotic mechanisms [5]. Superoxide dismutase (SOD) is an enzyme of cellular antioxidant defense system which counterbalances harmful reactive oxygen species (ROS) accumulated in cancer cells [6]. ROS has a vital role in autophagy which is necessary to satisfy the elevated nutrient requirement by the cancer cells [7]. Increased SOD level inhibits autophagy leading to subsequent cancer cell death. Therefore, targeting epigenetically altered p53, Bcl2, and SODmediated interlinked apoptotic networks may be a promising approach in the cross-talk of cancer therapy. As epigenetic changes are reversible and repairable, investigators are searching for molecules having the property of epigenetic inhibition in the vicinity of cancer drug discovery [8]. Although many of these epigenetic inhibitors are approved by the Food and Drug Administration (FDA) for their use in hematological cancers, they cause undesirable side effects to the normal tissue [8-10]. Therefore, researchers are in quest of an alternative and safe treatment strategy. Epidemiological surveys explore that people consuming a diet rich in fruits and vegetables are at very low risk of cancer $[2,11]$. Flavonoids are plant-derived bioactive secondary metabolites and well known for their anti-cancer potential through activating various molecular targets [2, 12, 13]. Silibinin (SBN) and quercetin (QCT) are two bioflavonoid compounds reported to exert chemoprevention in several forms of cancer and inhibit epigenetic alterations of many important genes [2, 14, 15]. Moreover, they are safe to the human body in terms of toxicity and side effects $[12,16]$.

Hence, it may be hypothesized that SBN and QCT alone or in combination might be attractive candidates for preventing cancer in older adults through hindering epigenetic alterations of genes involved in the apoptotic pathway when consumed consistently from the very young age of life. The main objective of the present study was to investigate the preventive anti-cancer efficacy of SBN and QCT in both in vitro and in vivo mouse lung and breast cancer xenograft models. Furthermore, we explored their involvement in triggering $\mathrm{p} 53, \mathrm{Bcl} 2$, and SOD-mediated apoptotic signaling cascade to impede cancer growth.

\section{Methods}

\section{Reagents}

QCT and SBN ( $>98 \%$ pure) were procured from Sigma Aldrich, India. Ketoconazole (tablets, Albatross pharmaceuticals, India), cyclosporine (ampoules, Biocon Ltd., India), cyclophosphamide (injections, Sigma-Aldrich), and ampoxin (Injections, Unichem laboratories, India) were used in the experiment. Roswell Park Memorial Institute (RPMI) 1640 medium, Fetal Bovine Serum (FBS), and antibiotic and antimycotic preparations were purchased from Gibco, USA. Trypsin EDTA solution and 3(4,5-Dimethylthiazol-2-yl)-2,5-(Diphenyltetrazolium bromide) (MTT) were obtained from HiMedia laboratories Pvt. Ltd., India. TRIZOL reagent was purchased from Life technologies, Inc. USA. Verso cDNA synthesis kit and all PCR reagents were purchased from Thermo Scientific, EU. Primers were obtained from Sigma Aldrich, USA. Hoechst dye 43332 and PI were purchased from MP Biomedicals, USA.

\section{Cell lines}

A549 and MDA-MB-468 cell lines were procured from National Centre for Cell Lines (NCCS), Pune, India.

\section{Animals}

Male and female C57BL6 mice (weighing 10-15g, 3 weeks old) were obtained from Mahaveera Enterprises, Hyderabad, India (registration no. 1656/PO/bt/S/12/CPCSEA) and maintained at the animal house facility of B. V. Patel PERD Centre, Ahmedabad, India (registration no. 1661/ $\mathrm{PO} / \mathrm{Re} / \mathrm{S} / 12 / \mathrm{CPCSEA})$. All animals were housed in individually ventilated cage (IVC) system with an environment of $25 \pm 3{ }^{\circ} \mathrm{C}$ temperature, $60 \pm 5 \%$ humidity, $10 \%$ air exchange rate, and $12 \mathrm{~h}$ light and $12 \mathrm{~h}$ dark cycle.

\section{Cell culture}

The non-small cell lung cancer cell line A549 and triple negative breast cancer cell line MDA-MB-468 are very aggressive type and responsible for two most fatal cancer deaths of human beings. So these two cell lines were selected in our study for in vitro as well as in vivo assays. Cell lines were grown in tissue culture flasks containing RPMI 1640 medium and 10\% FBS in $\mathrm{CO}_{2}$ incubator at $37{ }^{\circ} \mathrm{C}$ temperature under a humidified atmosphere containing $5 \% \mathrm{CO}_{2}$. At $75-80 \%$ confluency, the cells were sub cultured by the treatment of Trypsin-EDTA solution.

\section{In vitro cytotoxicity assay}

Cytotoxicity of QCT and SBN against A549 and MDAMB-468 cell lines was performed by MTT assay [17]. $10^{4}$ cells per well were plated in 96 well plates and incubated at $37{ }^{\circ} \mathrm{C}$ in a $\mathrm{CO} 2$ incubator for $24 \mathrm{~h}$. Next cells were treated with different concentrations (25 to 250 $\mu \mathrm{M})$ of QCT and SBN and incubated for $48 \mathrm{~h}$. The cells were incubated with MTT solution $(5 \mathrm{mg} / \mathrm{ml})$ for an additional $4 \mathrm{~h}$ and the MTT solution was replaced with DMSO to solubilize the formazen crystal formed after reduction of the dye MTT by the mitochondrial dehydrogenase enzyme present in the live cells. The absorbance of each well was measured by a microplate 
reader (Biotek, USA) at $570 \mathrm{~nm}$ wavelength and percent cell viability was calculated using the formula:

$\%$ cell viability $=($ Absorbance of test $\times 100) /$ Absorbance of control

\section{Colony formation assay}

Colony formation assay was performed according to the protocol described by Xi-Yuan Ge et al. with some modifications [18]. Cells were seeded in 6 well plates at a density of 500 cells per well in triplicate and treated with SBN, QCT, and combination of SBN and QCT at near IC50 value. After 2 weeks of culture, the cells were fixed with $70 \%$ methanol, stained with crystal violet $(4 \mathrm{mg} / \mathrm{ml})$ and observed under the microscope. The number of colonies was counted and graphically expressed.

\section{In vitro apoptosis assay using fluorescence microscopy}

In total, $0.1 \times 10^{6}$ cells were seeded per well in a 12-well tissue culture plate in triplicate and incubated in a $\mathrm{CO} 2$ incubator for $24 \mathrm{~h}$. The cells were treated with SBN and QCT alone or in combination for $48 \mathrm{~h}$ at a concentration of near IC50 value. Next, the cells were washed with PBS and incubated with Hoechst dye $43332(5 \mu \mathrm{g} / \mathrm{ml})$ in dark for $15 \mathrm{~min}$ at room temperature. The cells were counterstained with propidium iodide (PI, $5 \mu \mathrm{g} / \mathrm{ml}$ ) and immediately visualized under the fluorescence microscope. Blue fluorescent dye Hoechst 33342 is permeable to the cell membrane and stains the nucleic acid of both live and dead cells, whereas red fluorescent dye PI binds with the DNA of the dead cells only [19]. The percentage of apoptotic cells was calculated among a minimum of 200 target cells within randomly selected fields and presented as mean $\pm \operatorname{SD}(n=3)[19,20]$.

Apoptotic cells $(\%)=(A) \times 100 /(L+D+A)$

Here, $L=$ live cells (chromatin stained blue and intact)

$D=$ dead cells (chromatin stained pink)

$A=$ cells with apoptotic nuclei (chromatin stained blue and fragmented)

\section{Qualitative gene expression analysis by reverse transcriptase PCR}

One million A549 or MDA-MB-468 cells per well were plated in 6 well plates and incubated for $24 \mathrm{~h}$ at $37^{\circ} \mathrm{C}$ in a $\mathrm{CO}_{2}$ incubator. The cells were treated with QCT and SBN alone or in combination and incubated for $48 \mathrm{~h}$. Total RNA was isolated from the cells of different treatment groups using TRIZOL reagent (Life Technologies, Inc. USA) and quantified spectrophotometrically (UV1800, Shimadzu, Japan). One microgram of RNA from each sample was used to synthesize cDNA using the Verso cDNA synthesis kit (Thermo Scientific, EU). cDNA was amplified using primers specific for p53, $\mathrm{Bcl} 2$, and GAPDH in gradient Veriti 96 well thermal cycler (Applied Biosystem, USA). The primers were designed using specific primer designing tool Primer3 and BLAST of NCBI (National Centre for Biotechnology Information) (Table 1). The thermal cycling conditions involved an initial denaturation at $94{ }^{\circ} \mathrm{C}$ for $90 \mathrm{~s}$ followed by 35 cycles of denaturation at $94{ }^{\circ} \mathrm{C}$ for $30 \mathrm{~s}$, annealing for $60 \mathrm{~s}$ at $59{ }^{\circ} \mathrm{C}$, and extension at $72{ }^{\circ} \mathrm{C}$ for 60 s. Finally, another extension was done at $72{ }^{\circ} \mathrm{C}$ for 600 s. Amplified PCR products were analyzed on 1.5\% agarose gel containing the stain ethidium bromide. The PCR products were normalized to amplified GAPDH which was considered as a housekeeping gene. The relative band intensities of various amplified products were calculated using the Image $\mathrm{J}$ software (Molecular Dynamics, Sunnyvale, CA).

\section{In vivo preventive anti-cancer potential of SBN and QCT}

Three weeks old healthy C57BL6 mice $(n=48)$ weighing 10-15 g were acclimatized, dosed and handled for the experiment as per CPCSEA guideline. The protocol of in vivo preventive anti-cancer activity (protocol no. PERD/ IAEC/2017/016) was reviewed and approved by the Institutional Animal Ethics Committee (IAEC) (Fig. 1). The mice were randomized and grouped as disease control (DC), the treatment I, treatment II, and treatment III (6 male and 6 female mice per group). DC mice were daily administered with $0.2 \%$ agar orally throughout the study. Treatments I and II groups received SBN $(200 \mathrm{mg} / \mathrm{kg})$ and QCT $(100 \mathrm{mg} / \mathrm{kg})$ respectively suspended in $0.2 \%$ agar by oral gavages till the end of the study. The mice of treatment group III were co-administered with SBN $(200 \mathrm{mg} /$ $\mathrm{kg})$ and QCT $(100 \mathrm{mg} / \mathrm{kg})$ in the entire experiment. At 8 weeks of age, animals were immunocompromised as per the protocol described by Jivrajani et. al. [21] and immunosuppression was confirmed by analyzing WBC counts of the mice. After successful immunocompromisation, male mice $(n=24)$ were injected with A549 cells (5 million cells/mouse) at the shoulder blade region subcutaneously and female mice $(n=24)$ were inoculated with MDA-MB-468 cells (5 million cells/mouse) in the mammary fat pad orthotopically. The tumor volume of mice of the DC group and all treatment groups were measured routinely using a vernier caliper. The morbidity, mortality, food intake, and body weight of the animals were recorded. After 5th week of xenograft implantation, the mice of the DC group appeared moribund due to the tumor burden. Therefore, the study was terminated. The animals were sacrificed by $\mathrm{CO}_{2}$ asphyxiation, the tumors were excised and preserved for further evaluations.

\section{Estimation of serum superoxide dismutase level}

At the termination of the experiment, the blood sample was withdrawn from the mice to separate serum and the SOD enzyme level was measured as per the protocol described by Marklund $S$ and Marklund $G$ [22] and 
Table 1 Sequence of primers used for gene amplification

\begin{tabular}{llll}
\hline Gene & Forward primer (5' to $\left.\mathbf{3}^{\prime}\right)$ & Reverse primer (3' to $\mathbf{5}^{\prime}$ ) & Amplicon size \\
\hline p53 & GGCGCACAGAGGAAGAGAT & CTTCAGGTGGCTGGAGTGAG & 266 \\
BCl2 & CCCGCGACTCCTGATTCATT & GTTCCCCCTTGGCATGAGA & 265 \\
GAPDH & CATGAGAAGTATGACAACAGCCT & CCGTTCAGCTCAGGGATGAC & 269 \\
\hline
\end{tabular}

modified by Gavali et al. [23]. SOD may prevent the auto-oxidation of pyrogallol of the test samples. Fifty percent inhibition of pyrogallol auto-oxidation per 3-ml assay mixture prepared with a serum sample of mice of different experimental groups was calculated and expressed as a unit of SOD enzyme present per $\mathrm{ml}$ of serum of mice. In this assay, one additional normal control group was included for comparison.

Units of $\mathrm{SOD} / 3 \mathrm{ml}$ of assay mixture $=[(\mathrm{A}-\mathrm{B}) /$ $(\mathrm{A} \times 50)] \times 100$

Unit $\times 10=$ Units $/ \mathrm{ml}$ of sample solution

Here, $A=$ absorbance reading of normal control, $B=$ absorbance reading of sample

\section{Oral toxicity study of SBN and QCT}

Twenty-eight days oral toxicity study was performed in healthy C57BL6 mice weighing 25-30 g (protocol no. PERD/IAEC/2017/018). Animals were divided into various groups ( $n=6$ per group), viz., (1) Normal control or NC (0.2\% agar), (2) SBN (600 mg/kg), (3) QCT (300 mg/kg), and (4) combination of SBN $(600 \mathrm{mg} / \mathrm{kg})$ and QCT $(300$ $\mathrm{mg} / \mathrm{kg}$ ). Clinical symptoms, food intake, body weight, hematological, biochemical parameters, and histopathological interpretation of vital organs were assessed

\section{Statistical analysis}

Statistical analysis was performed using the Graph Pad Prism 6.0 software. One-way analysis of variance (ANOVA) and paired $t$ test were used to determine the significant differences of groups. $p<0.05$ was accepted as statistically significant value.

\section{Results}

In vitro cell viability study of SBN and QCT

In vitro cytotoxicity of SBN and QCT was conducted in both A549 and MDA-MB-468 cell lines. Cells were treated with the two bioflavonoids at different concentrations for the duration of $48 \mathrm{~h}$ and the IC50 value was assessed.

Results indicated that SBN and QCT could inhibit cancer cell growth in a concentration-dependent manner (Fig. 2). The test compounds at rising concentration caused a significant reduction in cell viability of both A549 and MDA-MB-468 cells in comparison to the untreated control cells $(p<0.05)$. Table 2 showed the $50 \%$ growth inhibition concentrations (IC50) of SBN and QCT for both A549 and MDA-MB-468 cell lines after $48 \mathrm{~h}$ of incubation.

\section{Determination of colony formation efficiency}

The cancer cell lines have a trend to grow in colonies [18]. A549 and MDA-MB-468 cells were incubated with SBN and QCT at near IC50 value and their competence in colony formation was examined. The colonies consisting of a minimum number of 50 cells were considered for the evaluation. The number of the colonies formed in the treated cells were reduced significantly $(p<0.05)$ as compared to the untreated control cells (Fig. 3). As can be seen in Fig. 3c, the cotreatment of SBN and QCT significantly $(p<0.05)$ reduced the colony numbers as compared to separately SBN and QCT exposed cells. The size of the colonies of both A549 and MDA-MB-468 cell lines was noticeably shrunk after SBN, QCT, and combination of SBN and QCT treatment when compared with the control.

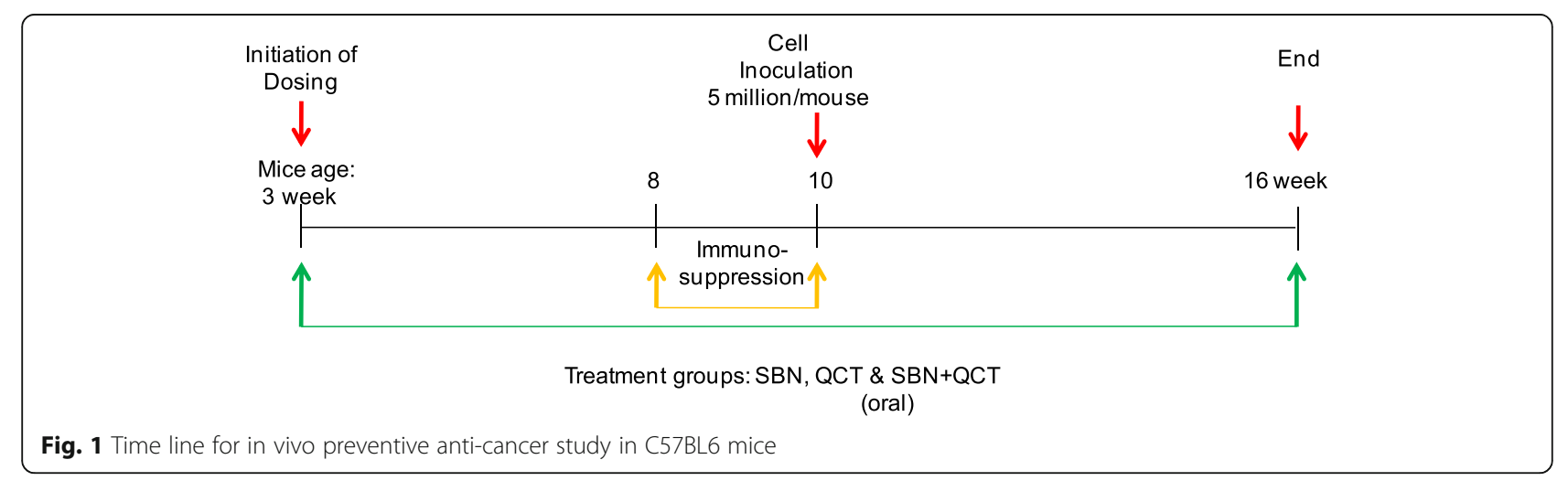



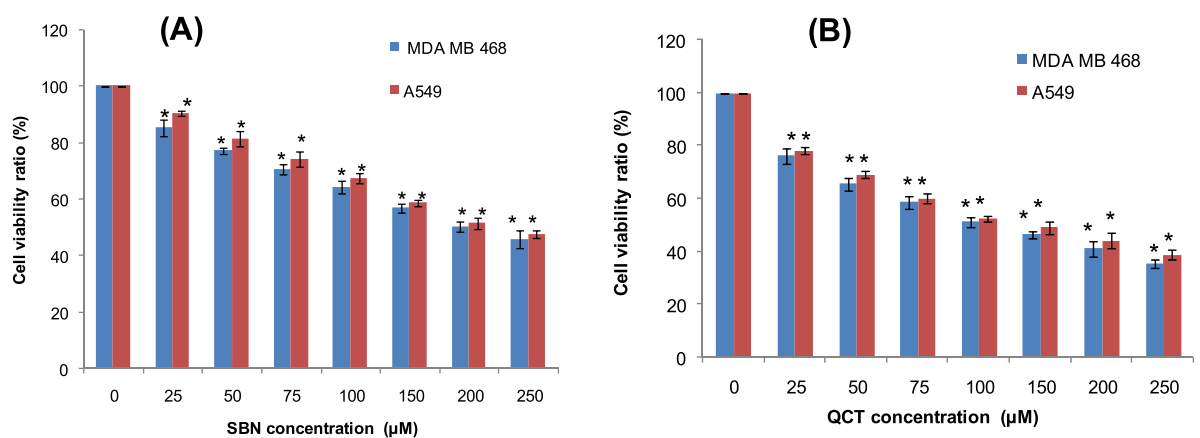

Fig. 2 Effect of (a) SBN and (b) QCT on the viability of MDA-MB-468 and A549 cell lines. All data represented as mean $\pm S D(n=3)$. Asterisk indicates a significant difference when compared to control, $p<0.05$

\section{Evaluation of in vitro apoptosis by SBN and QCT}

Apoptosis induces cellular morphology changes which comprise of chromatin condensation, pyknosis, or nuclear fragmentation and loss of cell membrane integrity $[20,24,25]$. A549 and MDA-MB-468 cell lines were incubated with SBN and QCT for the duration of $48 \mathrm{~h}$, stained with the fluorescent dyes, viz., Hoechst 33342 and PI and the number of apoptotic cells were interpreted under a fluorescence microscope. Hoechst 33342 can penetrate both live and dead cell membranes and stain the nuclei blue, whereas the red fluorescent stain PI is permeable to the dead or necrotic cells only [19]. Therefore, the nuclei normal and apoptotic cells of both control and treatment groups appeared intact and blue under the fluorescence microscope. However, the nuclei of the necrotic cells found to be pink owing to the costaining with both Hoechst 33342 and PI (Fig. 4a and b). The histogram in Fig. 4c depicts a significant increase in the percentage of apoptotic cells in SBN- and QCTtreated groups as compared to untreated control $(p<$ 0.05). However, co-treatment with SBN and QCT showed more prominent results in comparison of control and other individual treatment groups $(p<0.05)$ of both A549 and MDA-MB-468 cell lines.

\section{Reverse transcriptase PCR analysis and gene expression study}

A549 and MDA-MB-468 cell lines were treated with SBN and QCT alone or in combination for $48 \mathrm{~h}$. The expression of tumor suppressor gene p53 and oncogene $\mathrm{Bcl} 2$ of treated and untreated cancer cells was investigated by reverse transcriptase PCR technique. In most of the cancer cells, the p53 gene is inactivated or mutated,

Table 2 50\% growth inhibition concentration (IC50) of SBN and QCT

\begin{tabular}{lll}
\hline Name of drug & SBN $(\mu \mathrm{M})$ & QCT $(\mu \mathrm{M})$ \\
\hline IC50 for A549 cell line (mean \pm SD8) & $229.09 \pm 2.5$ & $132.8 \pm 2.7$ \\
IC50 for MDA-MB-468 cell line $($ mean \pm SD) & $208.93 \pm 2.79$ & $114.9 \pm 1.98$ \\
\hline
\end{tabular}

whereas anti-apoptotic gene $\mathrm{Bcl} 2$ is overexpressed [26, 27]. The cancer cell line A549 expresses wild type p53 with very low intensity owing to its reduced half-life and instability [28]. Although the p53 gene is mutated in MDA-MB-468 cell and highly expressed as the half-life of mutated p53 is more than its wild type counterpart [28]. As can be seen in Fig. 5, the expression of p53 and $\mathrm{Bcl} 2$ genes is prominently modulated after treating cells with SBN and QCT at their near IC50 value. Moreover, co-treatment with SBN and QCT significantly reversed the p53 and Bcl2 gene activity as compared to the individual SBN and QCT treated cells $(p<0.05)$. These findings were further confirmed by densitometric analysis.

\section{Investigation of in vivo chemopreventive potential of SBN and QCT}

Preventive anti-cancer efficacy of bioactive molecules SBN and QCT alone or in combination was evaluated in both lung and breast tumor xenograft model developed in C57BL6 mice. The treatment of the animals was initiated from the day of weaning and continued until the end of the study. The animals were successfully immunocompromised at 8 weeks of age and the cancer cell lines were inoculated. The results indicated that the tumor volume of the mice of the DC group increased incessantly and reached $>300 \mathrm{~mm}^{3}$ at the end of 5 th week of tumor xenograft implantation. However, SBN and QCT treatments markedly deliberated the tumor growth in the mice of both lung and breast tumor xenograft models. Figure $6 \mathrm{a}$ and $\mathrm{b}$ illustrate that the tumor progression of all treated mice was significantly less $(p<$ $0.05)$ as compared to their respective DC group. However, the tumor growth in the SBN and QCT co-treated mice was the least in comparison to the animals of other treatment groups. It was noticed that the DC mice of both A549 and MDA-MB-468 cell line induced cancer xenograft models gradually turn into morbid as a result of increased tumor burden. Interestingly, after 5 weeks of A549 cancer cells inoculation, the percentage of tumor growth prevention in SBN, QCT alone, and 

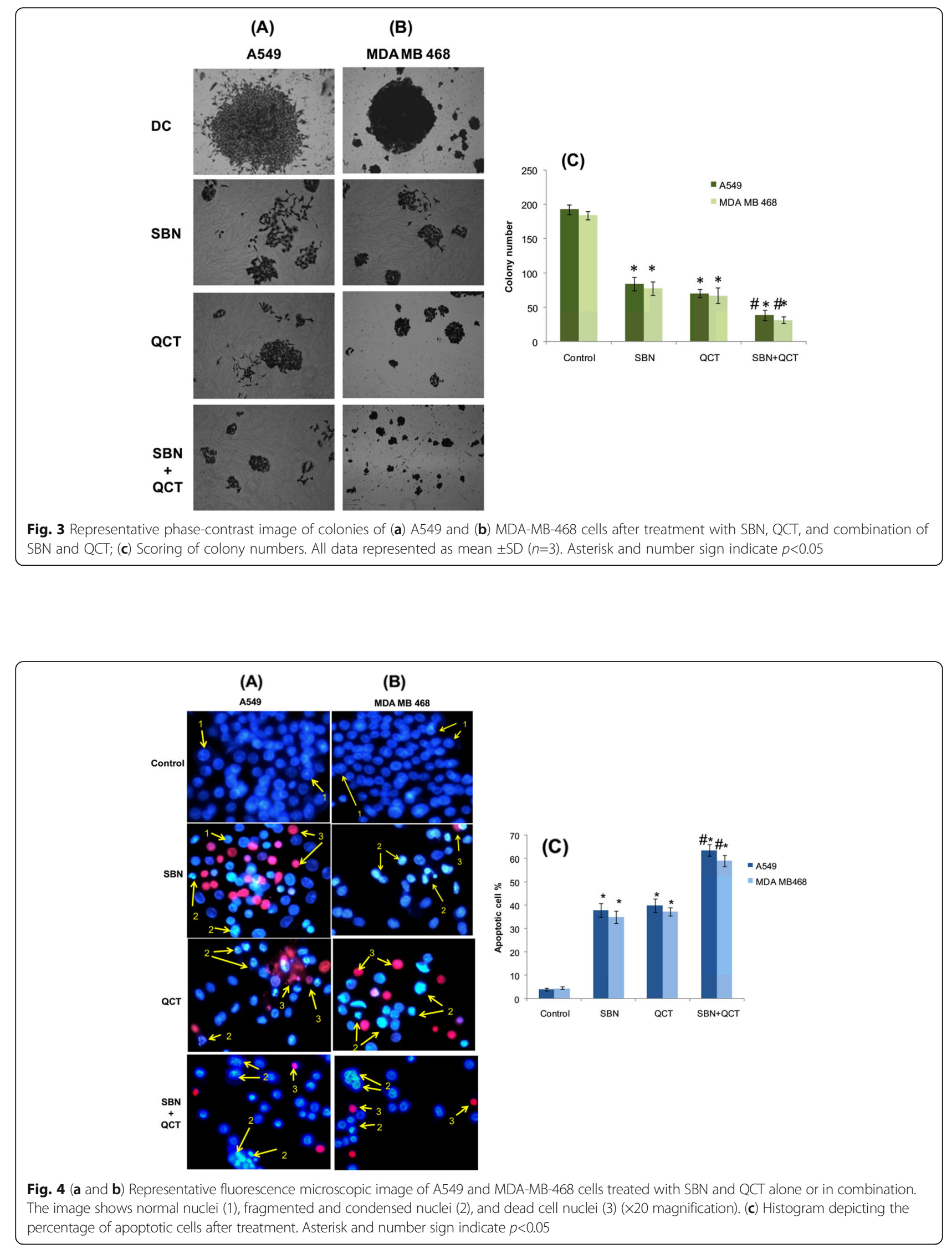
(i)

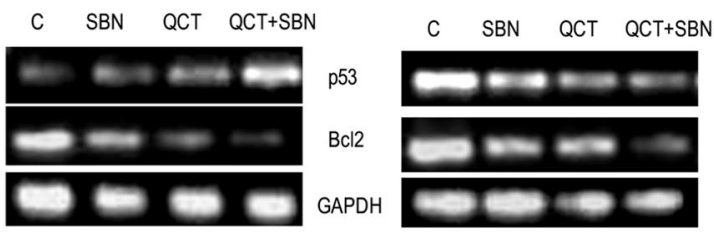

(A)

(B)

\section{(ii)}
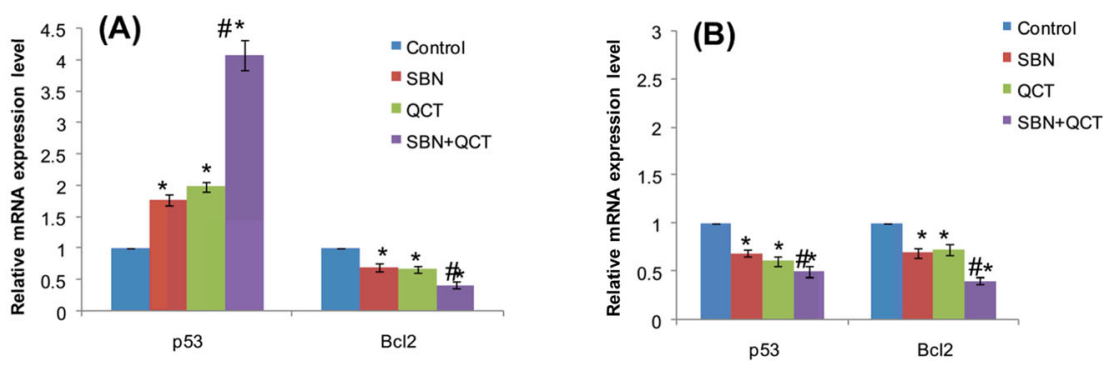

Fig. 5 Effect of SBN and QCT alone or in combination on p53 and Bcl2 genes expression in (a) A549 and (b) MDA-MB-468 cells. (i) Lane 1 shows the expression of $\mathrm{p} 53$ and $\mathrm{BC} 22$ genes in untreated cells. Lanes 2, 3, and 4 show the modulation in expression of these genes after treatment with $\mathrm{SBN}$ and QCT alone or in combination respectively. (ii) Values in the graphs are mean $\pm \mathrm{SD}$, where $n=3$. Asterisk and number sign indicate $p<0.05$

combination-treated groups in respect of the DC group were $29.21,35.87$, and 44.53 respectively, while in MDAMB-468 cell line induced breast tumor model the percentage change of tumor size in all three treatment groups was 28.44, 33.94, and 37.82 respectively. No significant change in the body weight and food consumption of the animals of the treatment groups was observed, although a marked reduction in both the parameters was found in DC animals (Fig. $6 \mathrm{v}$ and vi). Finally, the study was terminated at the end of 5th week of tumor cell line injection and the tumors were excised. It was noted that the excised tumor weights of all treatment groups were significantly less $(p<0.05)$ as compared to their respective DC groups.

\section{In vivo safety study}

Twenty-eight days oral toxicity study of SBN, QCT alone, and their combination was conducted in healthy C57BL6 mice at threefold higher dose levels than the animal effective doses used in the preventive anti-cancer study. No significant change in body weight, food consumption, and signs of intoxication were observed in the entire treatment groups. Hematology and serum biochemistry parameters of the animals were within the normal range. Furthermore, histopathological evaluation of vital organs of SBN and QCT co-treated mice unveiled normal tissue architectures (Fig. 7).

\section{Analysis of serum anti-oxidant enzyme level in mice}

SOD is a crucial enzyme of cellular antioxidant defense system [6]. The serum SOD enzyme level of animals of $\mathrm{NC}, \mathrm{DC}$, and all treatment groups was analyzed. Figure 8 illustrates a significant reduction in serum SOD activity of DC mice of both ectopic lung cancer and orthotopic breast cancer xenograft model in comparison to the normal control mice. Although serum SOD levels of the treatment groups were significantly elevated $(p<0.05)$ in contrast to their respective disease control groups (Fig. 8a and b), the mice co-treated with SBN and QCT exhibited the highest enzyme activity among all treatment groups.

\section{Discussion}

In spite of the recent remarkable advancement in the field of cancer diagnosis and therapy, the toxic side effect caused by chemotherapeutic drugs poses a big challenge [29]. Moreover, drug resistance and recurrence of the disease are the limitations of the chemotherapy treatment [29]. Wide research on cancer epigenetics and drug discovery helps investigators to synthesize novel molecules that can modulate the epigenetic alterations of cells and prevent cancer $[9,30]$. However, these "epidrugs" still have limitations owing to undesired toxicity to the cancer patients $[8,9]$. Hence, there is an urgent necessity to develop an alternative natural and safe treatment modality to combat cancer. Earlier reports corroborated that people receiving diet rich in fruits and vegetables have reduced the possibility of cancer [2]. Therefore, plant-derived natural compounds have gained great attention as potential candidates for chemoprevention [31-33]. The present research efforts uncovered interesting evidences of the therapeutic benefits of two promising bioactive molecules SBN and QCT in preventing cancer. SBN is a flavonolignan, a major class of flavonoid present in milk thistle plant (Silybum 

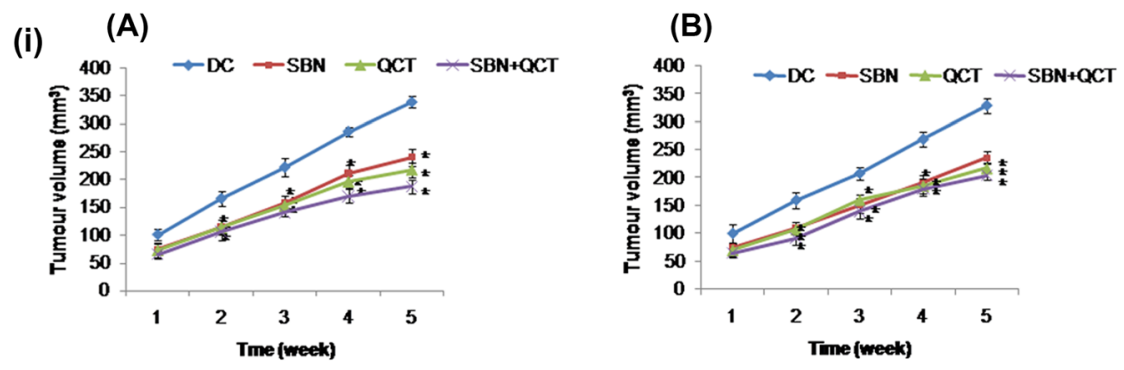

(ii)

(A)

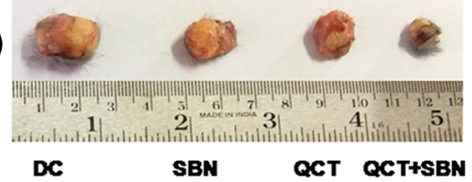

(B)

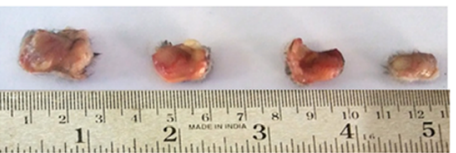

(iv)

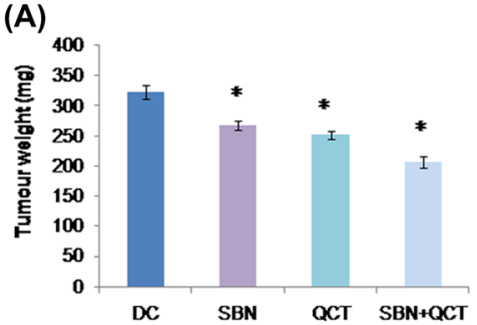

(v) (A)

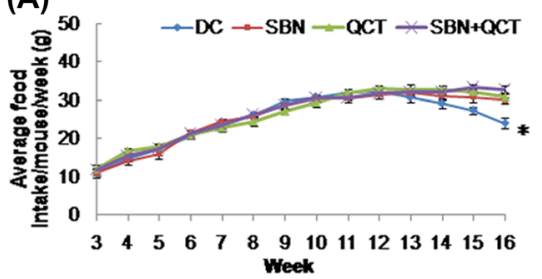

(vi)

(A)

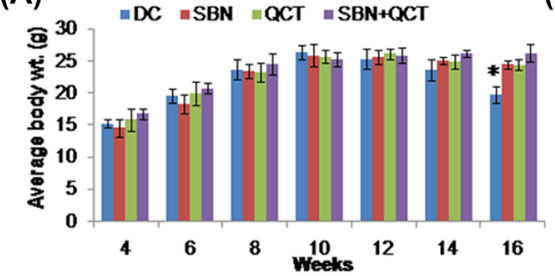

(A)

(B) (iii)
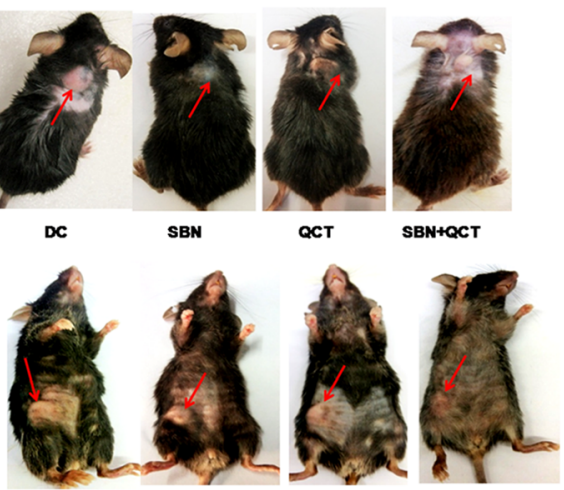

(B)

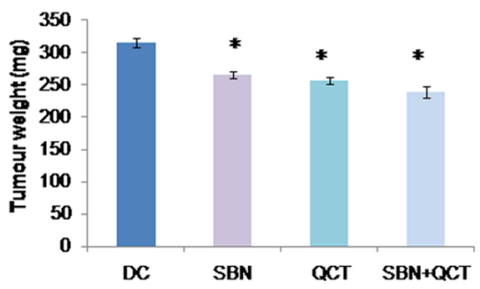

(B)

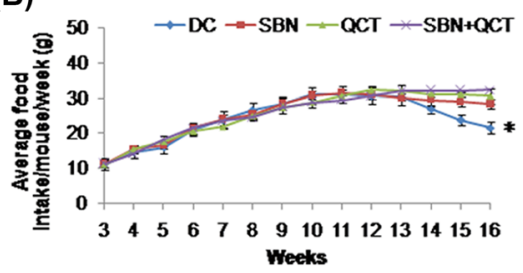

(B)

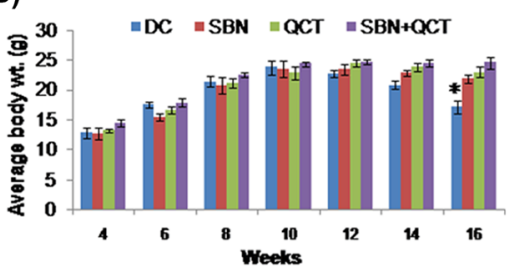

Fig. 6 Chemopreventive efficacy of SBN and QCT. (i) Graphical presentation of tumor volume; (ii) representative image of excised tumor; (iii) representative image of mice bearing tumor xenograft; (iv) graphical presentation of excised tumor weight; (v) weekly average food intake of mice; (vi) average bodyweight of mice at 2 weeks interval. In all figures (a) represent A549 and (b) depicts MDA-MB-468 cell-induced tumor xenograft model; Asterisk denotes $p<0.05$. Data represent mean $\pm S D, n=6$ per group 


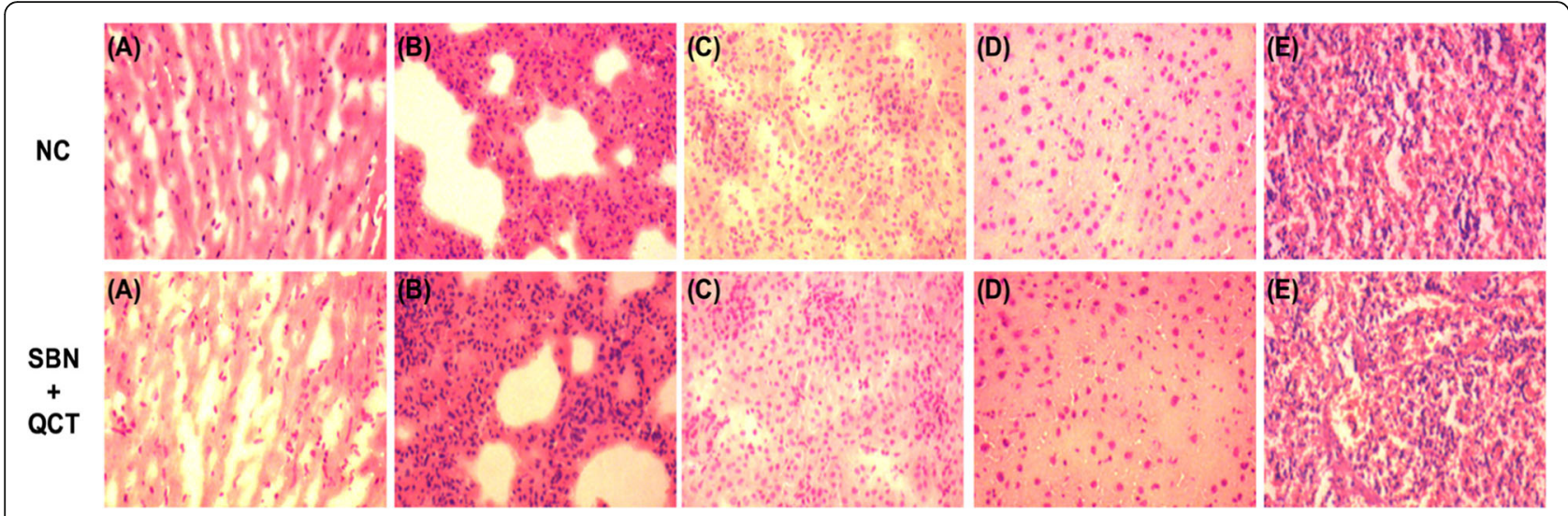

Fig. 7 Histopathology of vital organs of SBN and QCT co-treated mice (×20 magnification)

marianum) and used as hepatoprotectant for many years [34]. QCT belongs to another class of flavonoid, known as flavonol and abundantly found in fruits and vegetables [2, 35]. The class flavonoids comprises of a wide array of polyphenolic compounds that are well known for their anti-carcinogenic potential through activating various molecular targets [2]. Inclusion of the methyl group at $\mathrm{CpG}$ island of DNA and histone modification of certain crucial genes are the most common hallmark of cancer [36]. These aberrant epigenetic modifications cause silencing of tumor suppressor genes and activation of oncogenes [36, 37]. Earlier researchers reported that SBN and QCT act as epigenetic inhibitors $[14,15]$. They can inhibit cancer cell proliferation and trigger apoptosis by restoring functions of various epigenetically silenced TSGs [34, 38-40]. We explored the mechanism involved in inducing chemoprevention by the two natural "epi-drugs" SBN and QCT in both in vitro as well as in vivo models.

Apoptosis is the fundamental mechanism of normal cell growth and tissue development [25]. Deregulation of the apoptotic signaling cascade is associated with the development of deadly disease cancer [25]. An interlinking network of p53 (TSG), Bcl2 (proto-oncogene), and SOD antioxidant enzyme plays a significant role in counterbalancing cell survival and death $[5,41,42]$. p53, also known as the "guardian of cells" has an important role in cell growth and apoptosis [26, 42], whereas Bcl2 regulates the anti-apoptotic threshold of cells [5]. Previous articles reported that p53 may directly interact with $\mathrm{Bcl} 2$ leading to release of mitochondrial enzyme cytochrome-C and activates caspase-dependent apoptotic signaling pathway $[5,27]$

The link between the p53 gene and apoptosis has been illustrated in the myriad of articles. Under oxidative stress conditions, cells generate harmful ROS [43]. At physiological level, p53 activates the SOD enzyme and subsequently diminishes the accumulated ROS concentration in the cell [42]. This contributes to the repair of damaged DNA present in the cells [42]. On the other hand, reduced cellular level of ROS inhibits autophagy of adjoining stromal cells leading to the induction of apoptosis [2]. However, in acute stress conditions, hyper-active p53 instigates an imbalance in anti-oxidant gene function leading to decreased concentration of SOD enzyme resulting in upregulation of ROS level and stimulation of apoptotic pathway [42, 44].

Our results showed that SBN and QCT substantially restored the function of wild type p53 in A549 cells and reduced the p53 mutation intensity of breast cancer cell line MDA-MB-468. Furthermore, they inhibited the Bcl2
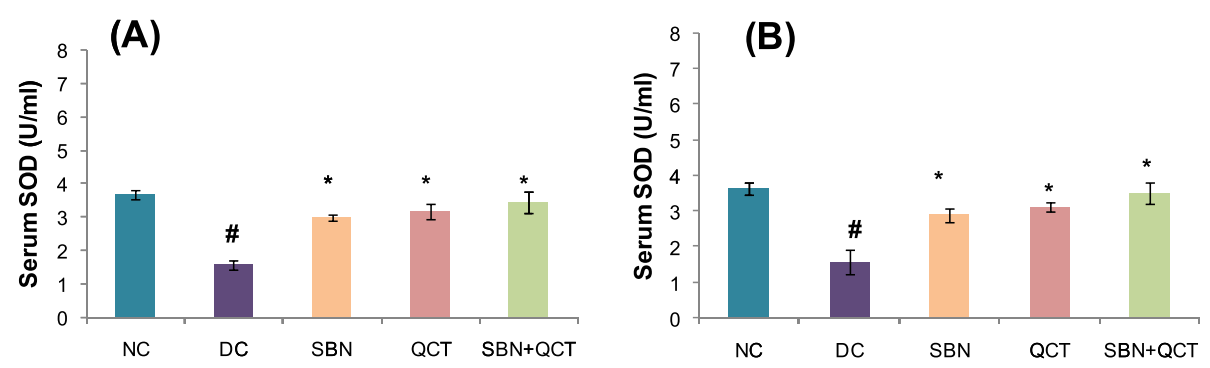

Fig. 8 Serum SOD enzyme level in mice with (a) A549 and (b) MDA-MB-468 cell lines induced tumor xenograft model after treatment with SBN and QCT alone or in combination. Asterisk indicates significant increase in SOD level in treatment groups as compared to DC group. Number sign indicates significant reduction of SOD activity in DC group in comparison of normal control mice $(p<0.05)$ 
oncogene overexpressed in both the cancer cells. In vitro fluorescence microscopy technique revealed that due to the treatment with SBN and QCT the nuclei of the cancer cells were noticeably fragmented, condensed, and necrosed.

SOD is a crucial enzyme of the body's antioxidant defense system which counterbalances the cellular toxic ROS level generated in diseased conditions [6]. Cancer cells are in demand for increased nutrition to meet their enhanced metabolic activity $[45,46]$. Accumulated ROS triggers autophagy of surrounding cells of cancer tissue and substantially enriches the cancer cells to grow rapidly $[7,46,47]$. Serum SOD enzyme assay exhibited that SBN and QCT alone and in combination significantly elevated the SOD level in tumor-bearing animals in comparison to untreated control groups. As serum represents the microenvironment of cells $[2,48]$, our result depicts the effect of the treatments in modulating cellular SOD concentration. Elevated SOD activity eventually neutralized the toxic ROS level and instigated cell suicidal machinery by hindering autophagy. Hence, accumulated evidence unveiled that SBN and QCTmodulated p53 and Bcl2 gene expression in both A549 and MDA-MB-468 cells. They also scavenged the harmful ROS present in the tumor microenvironment by uprising the serum SOD level. The activated p53, Bcl2, and SOD-mediated interlinked apoptotic networks helped in maintaining equilibrium between the cell death and survival. Our present results were in agreement with the previous investigations [49-51].
The preclinical cancer xenograft model developed in immunocompromised C57BL6 mice is widely used for testing the efficacy and safety of anti-cancer drugs [2, 52]. We evaluated in vivo chemopreventive activity of SBN and QCT in A549 cell line induced ectopic lung cancer and MDA-MB-468 cell line induced orthotropic breast cancer xenograft model in C57BL6 mice. From the ancient time, many researchers documented in their articles about the chemopreventive property of plant secondary metabolites and their role in cancer management $[53,54]$. We found that oral feeding of SBN and QCT alone or in combination from the day of weaning till the end of the study interestingly decelerated tumor growth and progression of mice at their adult age as compared to the DC mice. The induction of apoptosis is a common process to inhibit cancer cell proliferation. Our in vitro results showed that SBN and QCT promoted cancer cell death by reversing the epigenetically inactivated genes p53 and $\mathrm{Bcl} 2$ activity and subsequent triggering of $\mathrm{p} 53, \mathrm{Bcl} 2$, and SOD-mediated signaling pathway (Fig. 9). Epigenetic alteration is the primary cause of tumor cell development, although the loss of gene functions due to several epigenetic factors can be restored [8]. Hence, it can be assumed that the activation of $\mathrm{p} 53, \mathrm{Bcl} 2$, and SOD-mediated apoptotic cascade by SBN and QCT treatment might potentiate the prevention of tumor growth in C57BL6 mice.

Dose-accumulated side effects are the common drawbacks of chemotherapy treatment [29]. The harmful

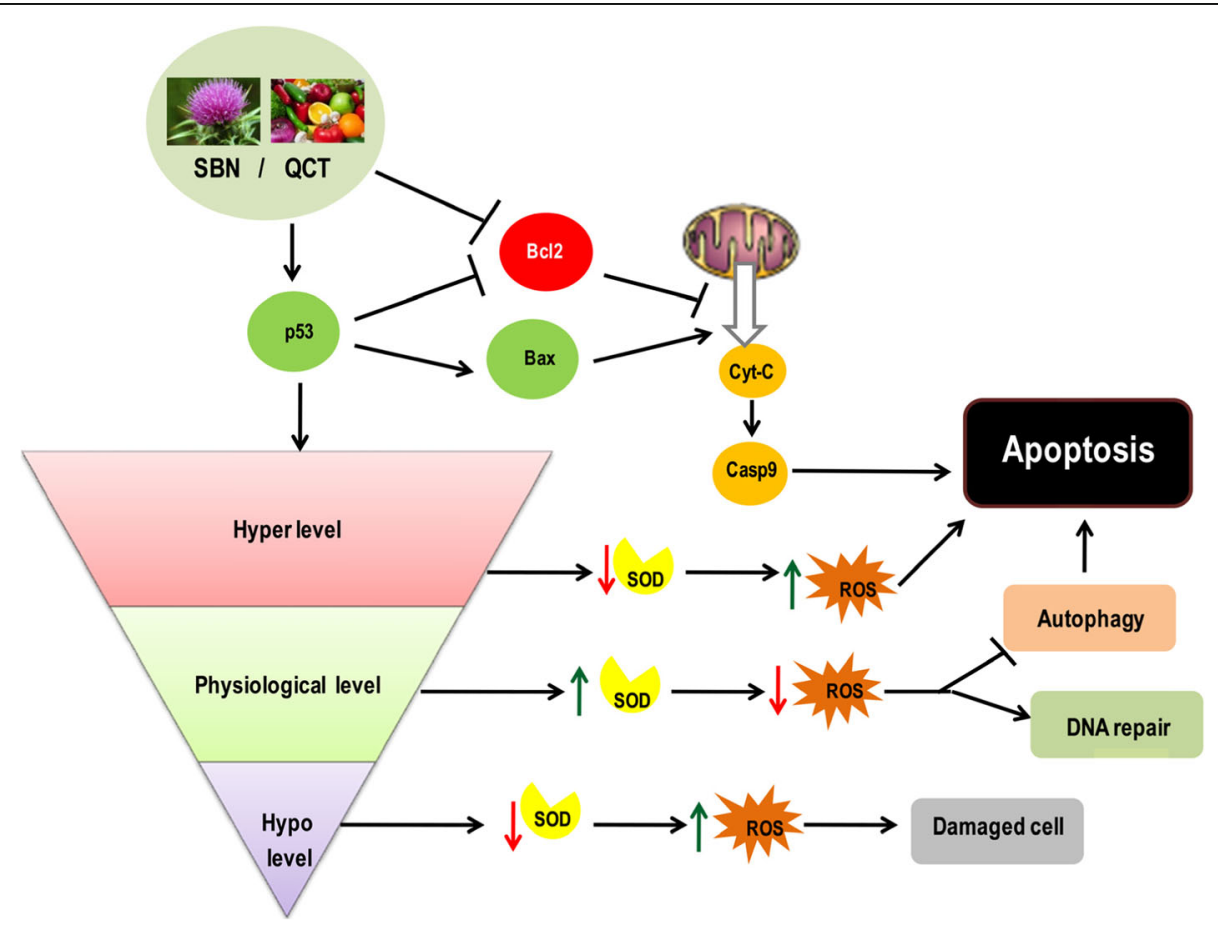

Fig. 9 A schematic diagram of SBN and QCT induced apoptotic signaling pathway 
toxicity of chemotherapeutic drugs associated with vomiting, anorexia, hair loss, cardiotoxicity, gastroenteritis, immune deficiency, and so on [55]. Serious health deterioration of the cancer patients limits the desired outcomes of the anti-cancer drugs [56]. Furthermore, drug resistance is a major loophole of anti-cancer therapy $[29,57]$. Scientists worldwide are searching for anti-carcinogenic drugs of plant origin with enhanced activity and no side effects. In the present study, we found that daily oral intake of SBN $(600 \mathrm{mg} / \mathrm{kg})$ and QCT $(300 \mathrm{mg} / \mathrm{kg})$ for the duration of 28 days was safe for the C57BL6 mice. There were no apparent changes in body weight, food intake, hematology, and serum biochemistry parameters of the animals observed. Moreover, no evidence of toxicity was noted among the SBN and QCT co-treated mice. In our previous article, we reported that intravenous administration of quercetin and its nanoformulation was well tolerated by the tumorbearing mice without manifestation of any marked side effects [2]. Our present observations added a further impact on the earlier findings.

\section{Conclusion}

Collectively, the present study indicates that SBN and QCT are the potential candidates in preventing lung and breast tumor growth via regulating p53, Bcl2, and SODmediated apoptotic signaling pathways. Furthermore, they show no apparent toxicity in mice even after prolonged oral administration. Therefore, it can be concluded that continuous dietary intake of two promising nutraceuticals SBN and QCT from the very early stage of life may prevent cancer development and progression in older adults. As prevention is always better than cure, hence, SBN and QCT may be consumed as dietary supplements to avoid deadly disease cancer. However, many phase-wise clinical trials are essential to further establish strong evidence supporting the present experimental outcomes.

\section{Abbreviations \\ QCT: Quercetin; SBN: Silibinin; FBS: Fetal bovine serum; MTT: 3-(4,5- Dimethylthiazol-2-yl)-2,5-(Diphenyltetrazolium bromide); DMSO: Dimethyl sulfoxide; ROS: Reactive oxygen species; SOD: Superoxide dismutase; DW: Deionized water; Fig: Figure; PCR: Polymerase chain reaction; NCBI: National Centre for Biotechnology Information; Bcl2: B-cell leukemia/ lymphoma 2; p53: Tumor protein 53; GAPDH: Glyceraldehyde 3-phosphate dehydrogenase; PI: Propidium iodide; NC: Normal control; DC: Disease control}

\section{Acknowledgements}

We would like to acknowledge the faculties and students of the department of Pharmacology and Toxicology of B. V. Patel Pharmaceutical Education and Research Development (PERD) Centre, Ahmedabad, for their support during research and NIRMA University, Ahmedabad.

\section{Authors' contributions}

RB performed the in vitro and in vivo studies and contributed majorly in writing the manuscript. RR assisted in interpretation of experimental data. $\mathrm{MN}$ contributed in writing the manuscript. All authors read and approved the final manuscript.
Funding

The authors acknowledge B. V. Patel Pharmaceutical Education and Research Development (PERD) Centre, Ahmedabad, Gujarat, India, for providing financial aid to carry out the research work.

\section{Availability of data and materials}

The authors confirm that all relevant data are present within the manuscript and its Supporting Information files. There is no restriction in the availability of data. Data and material are available upon request.

\section{Declarations}

Ethics approval and consent to participate

All the in vivo experiments were carried out as per the CPCSEA guideline. The animal study protocols (protocol no. PERD/IAEC/2017/016 and PERD/ IAEC/2017/018) were thoroughly reviewed and approved by the IAEC.

\section{Consent for publication}

Not applicable

\section{Competing interests}

The authors declare that they have no competing interests.

Received: 7 June 2020 Accepted: 23 February 2021

Published online: 20 March 2021

References

1. Bray F, Ferlay J, Soerjomataram I, Siegel RL, Torre LA, Jemal A (2018) Global Cancer Statistics 2018: GLOBOCAN estimates of incidence and Mmortality worldwide for 36 cancers in 185 countries. CA Cancer J Clin 68(6):394-424. https://doi.org/10.3322/caac.21492

2. Baksi R, Pratap D, Borse SP, Rana R, Sharma V, Nivsarkar M (2018) In vitro and in vivo anticancer efficacy potential of Quercetin loaded polymeric nanoparticles. Biomed Pharmacother 106:1513-1526. https://doi.org/10.101 6/j.biopha.2018.07.106

3. Ashe PC, Berry MD (2003) Apoptotic signaling cascades. Prog Neuropsychopharmacol Biol Psychiatry 27(2):199-214. https://doi.org/10.101 6/S0278-5846(03)00016-2

4. You JS, Jones PA (2012) Review cancer genetics and epigenetics: two sides of the same coin? Cancer Cell 22(1):9-20. https://doi.org/10.1016/j.ccr.2012. 06.008

5. Hemann MT, Lowe SW (2006) The p53 - Bcl-2 connection. Cell Death Differ 13(8):1256-1259. https://doi.org/10.1038/sj.cdd.4401962

6. Khan MA, Tania M, Zhang DZ, Chen HC (2010) Antioxidant enzymes and cancer. Chinese J. Cancer Res. 22(2):87-92. https://doi.org/10.1007/s11670-01 0-0087-7

7. Poillet-Perez L, Despouy G, Delage-Mourroux R, Boyer-Guittaut M (2015) Interplay between ROS and autophagy in cancer cells, from tumor initiation to cancer therapy. Redox Biol. 4:184-192. https://doi.org/10.1016/j.redox.2 014.12 .003

8. Jones PA, Baylin SB (2007) The epigenomics of cancer. Cell 128(4):683-692. https://doi.org/10.1016/j.cell.2007.01.029

9. Karberg S (2009) Switching on epigenetic therapy. Cell 139(6):1029-1031. https://doi.org/10.1016/j.cell.2009.11.038

10. Venturelli S, Berger A, Weiland T, Essmann F, Waibel M, Nuebling T, Häcker S, Schenk M, Schulze-Osthoff K, Salih HR, Fulda S (2013) Differential induction of apoptosis and senescence by the DNA methyltransferase inhibitors 5azacytidine and 5-aza-2'-deoxycytidine in solid tumor cells. Mol Cancer Ther 12(10):2226-2236. https://doi.org/10.1158/1535-7163.MCT-13-0137

11. Khan MA, Sundaram MK, Hamza A, Quraishi U, Gunasekera D, Ramesh L, Goala P, Al Alami U, Ansari MZ, Rizvi TA, Sharma C (2015) Sulforaphane reverses the expression of various tumor suppressor genes by targeting DNMT3B and HDAC1 in human cervical cancer cells. Evidence-Based Complement Altern Med 2015:1-12. https://doi.org/10.1155/2015/412149

12. Liao CY, Lee CC, Tsai CC, Hsueh CW, Wang CC, Chen I, Tsai MK, Liu MY, Hsieh AT, Su KJ, Wu HM (2015) Novel investigations of flavonoids as chemopreventive agents for hepatocellular carcinoma. Biomed Res Int 2015: 1-26. https://doi.org/10.1155/2015/840542

13. Neuhouser ML (2004) Dietary flavonoids and cancer risk: evidence from human population studies. Nutr Cancer 50(1):1-7. https://doi.org/10.1207/s1 5327914nc5001_1 
14. Nair HK, Rao KVK, Aalinkeel R, Mahajan S, Chawda R, Schwartz SA (2004) Inhibition of prostate cancer cell colony formation by the flavonoid quercetin correlates with modulation of specific regulatory genes. Clin Diagn Lab Immunol 11(1):63-69. https://doi.org/10.1128/CDLI.11.1.63-69.2004

15. Anestopoulos I, Sfakianos AP, Franco R, Chlichlia K, Panayiotidis MI, Kroll DJ, Pappa A (2017) A novel role of silibinin as a putative epigenetic modulator in human prostate carcinoma. Molecules 22(1):1-17. https://doi.org/10.3390/ molecules22010062

16. Singh RP, Mallikarjuna GU, Sharma G, Dhanalakshmi S, Tyagi AK, Chan DC, Agarwal C, Agarwal R (2004) Oral silibinin inhibits lung tumor growth in athymic nude mice and forms a novel chemocombination with doxorubicin targeting nuclear factor $\mathrm{kB}$ - mediated inducible chemoresistance. Clin Cancer Res 10(24):8641-8647. https://doi.org/10.11 58/1078-0432.CCR-04-1435

17. Shaikh MV, Kala M, Nivsarkar M (2017) Formulation and optimization of doxorubicin loaded polymeric nanoparticles using Box-Behnken design: exvivo stability and in-vitro activity. Eur J Pharm Sci 100:262-272. https://doi. org/10.1016/j.ejps.2017.01.026

18. Ge X-Y, Yang L-Q, Jiang Y, Yang WW, Fu J, Li SL (2014) Reactive oxygen species and autophagy associated apoptosis and limitation of clonogenic survival induced by zoledronic acid in salivary adenoid cystic carcinoma cell line SACC83. PLoS One 9(6):1-10. https://doi.org/10.1371/journal.pone.0101207

19. Rahman SN, Wahab NA, Abd Malek SN (2013) In vitro morphological assessment of apoptosis induced by antiproliferative constituents from the rhizomes of Curcuma zedoaria. Evidence-Based Complement Altern Med: eCAM 2013:doi.org/10.1155/2013/257108

20. Ulukaya E, Acilan C, Ari F, Ikitimur E, Yilmaz Y (2011) A Glance at the methods for detection of apoptosis qualitatively and quantitatively. Turk J Biochem 36(3):261-269

21. Jivrajani M, Shaikh MV, Shrivastava N, Nivsarkar M (2014) An improved and versatile immunosuppression protocol for the development of tumor xenograft in mice. Anticancer Res 34(12):7177-7183

22. Marklund S, Marklund G (1974) Involvement of the superoxide anion radical in the autoxidation of pyrogallol and a convenient assay for superoxide dismutase. Eur J Biochem 47(3):469-474. https://doi.org/10.1111/j.1432-1 033.1974.tb03714.x

23. Gavali Y, Deore D, Surwase SP, Zingade U (2013) Study of the serum superoxide dismutase levels in smoking and non-smoking patients with COPD. Int J Recent Trends Sci Technol 5(3):121-126

24. Mandelkow R, Gümbel D, Ahrend H, Kaul A, Zimmermann U, Burchardt M, Stope MB (2017) Detection and quantification of nuclear morphology changes in apoptotic cells by fluorescence microscopy and subsequent analysis of visualized fluorescent signals. Anticancer Res 37(5):2239-2244. https://doi.org/10.21873/anticanres.11560

25. Zamai L, Canonico B, Luchetti F, Ferri P, Melloni E, Guidotti L, Cappellini A, Cutroneo G, Vitale M, Papa S (2001) Supravital exposure to propidium iodide identifies apoptosis on adherent cells. Cytometry: The J Int Society for Analytical Cytology 64(1):57-64. https://doi.org/10.1002/1097-0320

26. Jin M, Park IA, Kim JY, Chung YR, Im SA, Lee KH, Moon HG, Han W, Noh DY, Ryu HS (2016) New insight on the biological role of p53 protein as a tumor suppressor: re-evaluation of its clinical significance in triple-negative breast cancer Tumor Biol 37(8):11017-11024. https://doi.org/10.1007/s13277-016-4990-5

27. Kong C, Zhang Z (2013) BCl-2 overexpression inhibits generation of intracellular reactive oxygen species and blocks adriamycin-induced apoptosis in bladder cancer cells. Asian Pac J Cancer Prev 14(2):895-901. https://doi.org/10.7314/APJCP.2013.14.2.895

28. Kaabinejadian S, Fouladdel S, Ramezani M, Azizi E (2008) p53 Expression in MCF7, T47D and MDA-MB 468 breast cancer cell lines treated with adriamycin using RT-PCR and immunocytochemistry. J Biol Sci 8(2):380-385. https://doi.org/10.3923/jbs.2008.380.385

29. Lin CH, Chang CY, Lee KR, Lin HJ, Chen TH, Wan L (2015) Flavones inhibit breast cancer proliferation through the Akt/FOXO3a signaling pathway. BMC Cancer 15(1):1-12. https://doi.org/10.1186/s12885-015-1965-7

30. Yoo CB, Cheng JC, Jones PA (2004) Zebularine: a new drug for epigenetic therapy. Biochem Soc Trans 32:910-912. https://doi.org/10.1042/BST0320910

31. Iwashita K, Kobori M, Yamaki K, Tsushida T (2014) Flavonoids inhibit cell growth and induce apoptosis in B16 melanoma 4A5 cells. Biosci Biotechnol Biochem 64(9):1813-1820. https://doi.org/10.1271/bbb.64.1813

32. Williams RJ, Spencer JP, Rice-Evans C (2004) Flavonoids: antioxidants or signalling molecules? Free Radic Biol Med 36(7):838-849. https://doi.org/10.1 016/j.freeradbiomed.2004.01.001
33. Ramos S (2007) Effects of dietary flavonoids on apoptotic pathways related to cancer chemoprevention. J Nutr Biochem 18(7):427-442. https://doi.org/1 0.1016/j.jnutbio.2006.11.004

34. Molavi O, Narimani F, Asiaee F, Sharifi S, Tarhriz V, Shayanfar A, Hejazi M, Lai R (2017) Silibinin sensitizes chemo-resistant breast cancer cells to chemotherapy. Pharm Biol 55(1):729-739. https://doi.org/10.1080/138802 09.2016 .1270972

35. Zhang YY, Yang Y, Tang K, Hu X, Zou G (2008) Physicochemical characterization and antioxidant activity of quercetin-loaded chitosan nanoparticles. J Appl Polym Sci 107(2):891-897. Doi. https://doi.org/10.1 002/App.26402

36. Esteller M (2006) Epigenetics provides a new generation of oncogenes and tumour-suppressor genes. Br J Cancer 94(2):179-183. https://doi.org/10.103 8/sj.bjc.6602918

37. Perri F, Longo F, Giuliano M, Sabbatino F, Favia G, Ionna F, Addeo R, Scarpati GD, Di Lorenzo G, Pisconti S (2017) Epigenetic control of gene expression: potential implications for cancer treatment. Crit Rev Oncol / Hematol 111:166-172. https://doi.org/10.1016/j.critrevonc.2017.01.020

38. Murakami A, Ashida H, Terao J (2008) Multitargeted cancer prevention by quercetin. Cancer Lett. 269(2):315-325. https://doi.org/10.1016/j.canlet.2008. 03.046

39. Wang L, Lee IM, Zhang SM, Blumberg JB, Buring JE, Sesso HD (2009) Dietary intake of selected flavonols, flavones, and flavonoid-rich foods and risk of cancer in middle-aged and older women. Am J Clin Nutr 89(3):905-912. https://doi.org/10.3945/ajcn.2008.26913

40. Bosch-barrera J, Menendez JA (2015) Silibinin and STAT3: a natural way of targeting transcription factors for cancer therapy. CANCER Treat Rev 41 (6): 540-546. https://doi.org/10.1016/j.ctrv.2015.04.008

41. Deng X, Gao F, May WS Jr (2016) Bcl2 retards G1/S cell cycle transition by regulating intracellular ROS. Blood 102(9):3179-3186. https://doi.org/10.11 82/blood-2003-04-1027

42. Vurusaner B, Poli G, Basaga H (2012) Tumor suppressor genes and ROS: complex networks of interactions. Free Radic Biol Med 52(1):7-18. https:// doi.org/10.1016/j.freeradbiomed.2011.09.035

43. Schieber M, Chandel NS (2014) ROS function in redox signaling and oxidative stress. Curr Biol 24(10):R453-R462. https://doi.org/10.1016/j.cub.2 014.03.034

44. Liu B, Chen Y, Clair DK (2008) ROS and p53: a versatile partnership. Free Radic Biol Med 44(8):1529-1535. https://doi.org/10.1016/j.freeradbiomed.2 008.01.011

45. Eng CH, Abraham RT (2011) The autophagy conundrum in cancer: influence of tumorigenic metabolic reprogramming. Oncogene 30(47):4687-4696. https://doi.org/10.1038/onc.2011.220

46. Noda N, Wakasugi H (2001) Cancer and oxidative stress. Jmaj 44(12):535539. https://doi.org/10.1016/0891-5849(90)90762-8

47. Nishikawa M (2008) Reactive oxygen species in tumor metastasis. Cancer Lett. 266(1):53-59. https://doi.org/10.1016/j.canlet.2008.02.031

48. Barata C, Varo I, Navarro JC, Arun S, Porte C (2005) Antioxidant enzyme activities and lipid peroxidation in the freshwater cladoceran Daphnia magna exposed to redox cycling compounds. Comp Biochem Physiol - C Toxicol Pharmacol 140(2):175-186. https://doi.org/10.1016/j.cca.2005.01.013

49. Kuo PC, Liu HF, Chao Jl (2004) Survivin and p53 modulate quercetininduced cell growth inhibition and apoptosis in human lung carcinoma cells. J Biol Chem 279(53):55875-55885. https://doi.org/10.1074/jbc.M4 07985200

50. Vijayababu MR, Kanagaraj P, Arunkumar A, llangovan R, Dharmarajan A, Arunakaran J (2006) Quercetin induces p53-independent apoptosis in human prostate cancer cells by modulating $\mathrm{BCl}-2$-related proteins: a possible mediation by IGFBP-3. Oncol Res 16(2):67-74. https://doi.org/10.372 7/000000006783981224

51. Pirouzpanah MB, Sabzichi M, Pirouzpanah S, Chavoshi H, Samadi N (2015) Silibilin-induces apoptosis in breast cancer cells by modulating p53, p21, Bak and Bcl-xl pathways. Asian Pacific J Cancer Prev 16(5):2087-2092

52. Jivrajani M, Nivsarkar M (2016) Ligand-targeted bacterial minicells: futuristic nano-sized drug delivery system for the efficient and cost effective delivery of shRNA to cancer cells. Nanomedicine Nanotechnology, Biol Med 12(8): 2485-2498. https://doi.org/10.1016/j.nano.2016.06.004

53. Ben-Arye E, Schiff E, Hassan E, Mutafoglu K, Lev-Ari S, Steiner M, Lavie O, Polliack A, Silbermann M, Lev E (2012) Integrative oncology in the Middle East: from traditional herbal knowledge to contemporary cancer care. Ann Oncol 23(1):211-221. https://doi.org/10.1093/annonc/mdr054 
54. Amin A, Gali-Muhtasib H, Ocker M, Schneider-Stock R (2009) Overview of major classes of plant-derived anticancer drugs. Int. J. Biomed. Sci. 5(1):1-11

55. Klener P (1999) Chemotherapy side effects and their management. Basic Clin Oncol 19:279-295

56. Love RR, Leventhal H, Easterling DV, Nerenz DR (1989) Side effects and emotional distress during cancer chemotherapy. Cancer 63(3):604-612. https://doi.org/10.1002/1097-0142(19890201)63:3<604::AID-CNCR2820630334 $>3.0 . \mathrm{CO}_{2} 2-2$

57. Singh RP, Mallikarjuna GU, Sharma G, Dhanalakshmi S, Tyagi AK, Chan DC, Agarwal C, Agarwal R (2004) Oral silibinin inhibits lung tumor growth in athymic nude mice and forms a novel chemocombination with doxorubicin targeting nuclear factor KB- mediated inducible chemoresistance. Clin Cancer Res 10(24):8641-8647. https://doi.org/10.1158/1078-0432.CCR-04-1435

\section{Publisher's Note}

Springer Nature remains neutral with regard to jurisdictional claims in published maps and institutional affiliations.

\section{Submit your manuscript to a SpringerOpen ${ }^{\circ}$ journal and benefit from:}

- Convenient online submission

- Rigorous peer review

- Open access: articles freely available online

High visibility within the field

- Retaining the copyright to your article 